\title{
Diurnal Changes of Transmission Time in the Arctic Propagation of VLF Waves
}

\author{
W. T. Blackband \\ Contribution from the Royal Aircraft Establishment, Farnborough, Hants, England
}

(Received September 10, 1963)

\begin{abstract}
The diurnal variation of the transmission time for the signal from a distant VLF transmitter results from the solar illumination of the lower ionosphere. For a path crossing the Arctic regions there will be no diurnal change for that part of the path which is illuminated by the midnight sun. It is shown that for a path crossing the Arctic Circle the diurnal change curve is of the normal trapesium shape at the equinoxes but that it takes on different forms at midsummer and midwinter. An analysis of experimental curves shows that they are of the form predicted. A simple rule for computing the change over on Arctic path is shown to agree well with the experimental data available.
\end{abstract}

\section{Introduction}

The diurnal variations in the transmission time for signals received at VLF have been studied in some detail for transmission paths in the lower latitudes but propagation in the Arctic regions has not been studied as closely. The two factors which introduce complexity into the changes over Arctic paths are

(a) the periods of $24 \mathrm{hr}$ daylight or darkness at certain seasons,

(b) the large differences in local time between the ends of relatively short great circle paths.

During the midsummer period of 1961 experimental observations of the diurnal variations in transmission time have been made at two points within the Arctic Circle, Bodø in Norway and Sondrestrom in Greenland, and also in Farnborough for the path to Seattle which lies partly within the Arctic Circle.

In this paper an explanation is given of the mechanism of these changes, and predicted changes are compared with those observed. The experimental data relate to frequencies in the VLF band between 16 and $20 \mathrm{kc} / \mathrm{s}$.

\section{Diurnal Change in Phase at Middle Latitudes}

This change is brought about by the change in the apparent height of the ionosphere. For rays near normal incidence this change is from about $90 \mathrm{~km}$ in darkness to about $72 \mathrm{~km}$ in full daylight, near glancing incidence these heights are somewhat less. In figure 1 is shown a ray from a transmitter $T$ reflected from the ionosphere to a receiver $R$. If the receiver is west of the transmitter, then when it is midnight at $T$, the path will all be in darkness and the ionosphere will be at its full height of $90 \mathrm{~km}$.

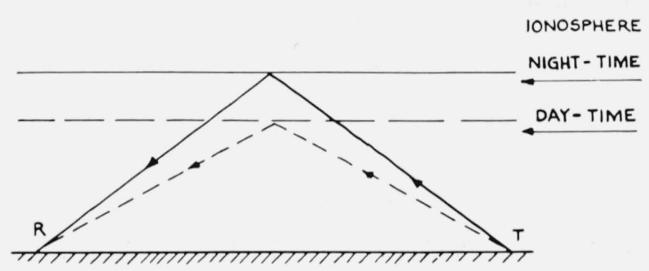

Figure 1. Reflections of signal from the ionosphere by day and by night.

Between the times of dawn at the receiver $\left(D_{R}\right)$ and sunset at the transmitter $\left(S_{T}\right)$, the whole path is in daylight and the ionosphere is at its lower height of about $72 \mathrm{~km}$.

During the daytime the ray between $T$ and $R$ will follow the dotted path of figure 1 which is shorter than the path up to the nighttime reflecting level which is shown with a full line. This reduction in path length reduces the transit time of the ray by $\Delta t$, this change being apparent as an advance in the phase of the received signal. While the value of $\Delta t$ over a given path is largely independent of frequency, the phase change varies almost linearly with frequency and for this reason the diurnal phase changes observed at different frequencies are most conveniently compared on the basis of their equivalent time delays.

Between the periods of all darkness and all light along the path $T R$ there are two periods of changing state when the transit time has intermediate values. These are shown by the sloping parts of the graph of figure 2. At ranges above $4500 \mathrm{~km}$ where mode interference cannot complicate the pattern, the joins of the two steady states are approximately straight with fairly definite angles to the "diurnal change trapezium," $-D_{T} D_{R} S_{T} S_{R}$.

The variation of $\Delta t$ with length of transmission path has been discussed previously [Blackband, 


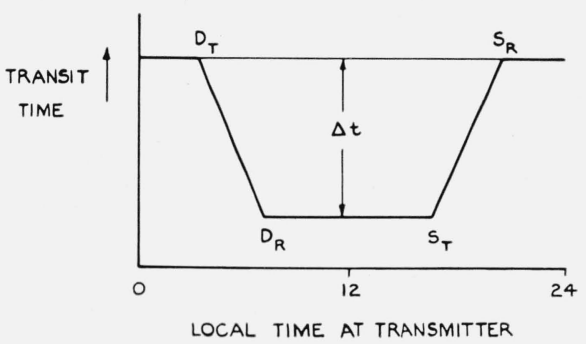

Figure 2. The diurnal change trapezium.

1961 and 1963]. A curve based on measured data is drawn with a solid line in figure $3 .^{1}$ In this figure a dotted line shows the variation of $\Delta t$ against distance for the first waveguide mode of propagation [Blackband, 1963]. The displacement of the solid from the dotted line is a measure of the effect of the higher order waveguide modes which only propagate with appreciable amplitude to distances of up to about $4500 \mathrm{~km}$ from the transmitter. The slope of the dotted line represents a change in velocity of about 1 in 400 from day to night.

\section{Diurnal Change in Transmission Time Over Arctic Paths}

The details of the diurnal change in transmission time brought about by the change in ionospheric height are illustrated in figure 4 in which the upper

1 This curve shows the change for the total skywave. In practical applications the large values of $\Delta t$ at short ranges are not apparent, being masked by the ground ray. diagram shows on a polar gnomonic projection the North Pole, and Arctic Circle. On midsummer day the line $A B$ dividing the dark and light hemispheres of the earth's surface will be tangential to the Arctic Circle, and will appear to roll around this as the earth rotates. Consider a transmitter sited at $T$, and a receiver at $R_{1}$. The inset (a) shows the diurnal variation observed at $R_{1}$, transmission time being plotted against local time at $T$. Starting at midnight with the whole path $T R_{1}$ in darkness and the apparent height of the ionosphere at its nighttime value, the delay is at its greatest. It will continue at this value as $A B$ rolls around until the time $D_{T}$ when it is dawn at $T$. The effective height of the ionosphere then begins to decrease progressively along the path until $D_{R}$ when it is dawn at $R_{1}$. This decrease is accompanied by a reduction in delay. Through the day the transmission time remains constant until sunset at $R$ which occurs at a time $S_{R}$, after this darkness spreads north until at $S_{T}$ the whole path is in darkness and the delay returns to its midnight value.

This diurnal change exhibits the "diurnal change trapezium" discussed in section 2. However, more complex forms of pattern are possible. Some of these are shown in insets (b), (c), and (d).

Consider a receiver at $R_{2}$ sited so that dawn reaches both $T$ and $R_{2}$ at the same time. As $D_{T}$ and $D_{R}$ occur at the same time the left-hand side of the pattern in the corresponding inset (b) shows a steep step, and the right-hand side is correspondingly reduced in slope. It is to be noted that at high latitudes the change from (a) to (b) can result from only a small change in the position of the receiver, such as from $R_{1}$ to $R_{2}$.

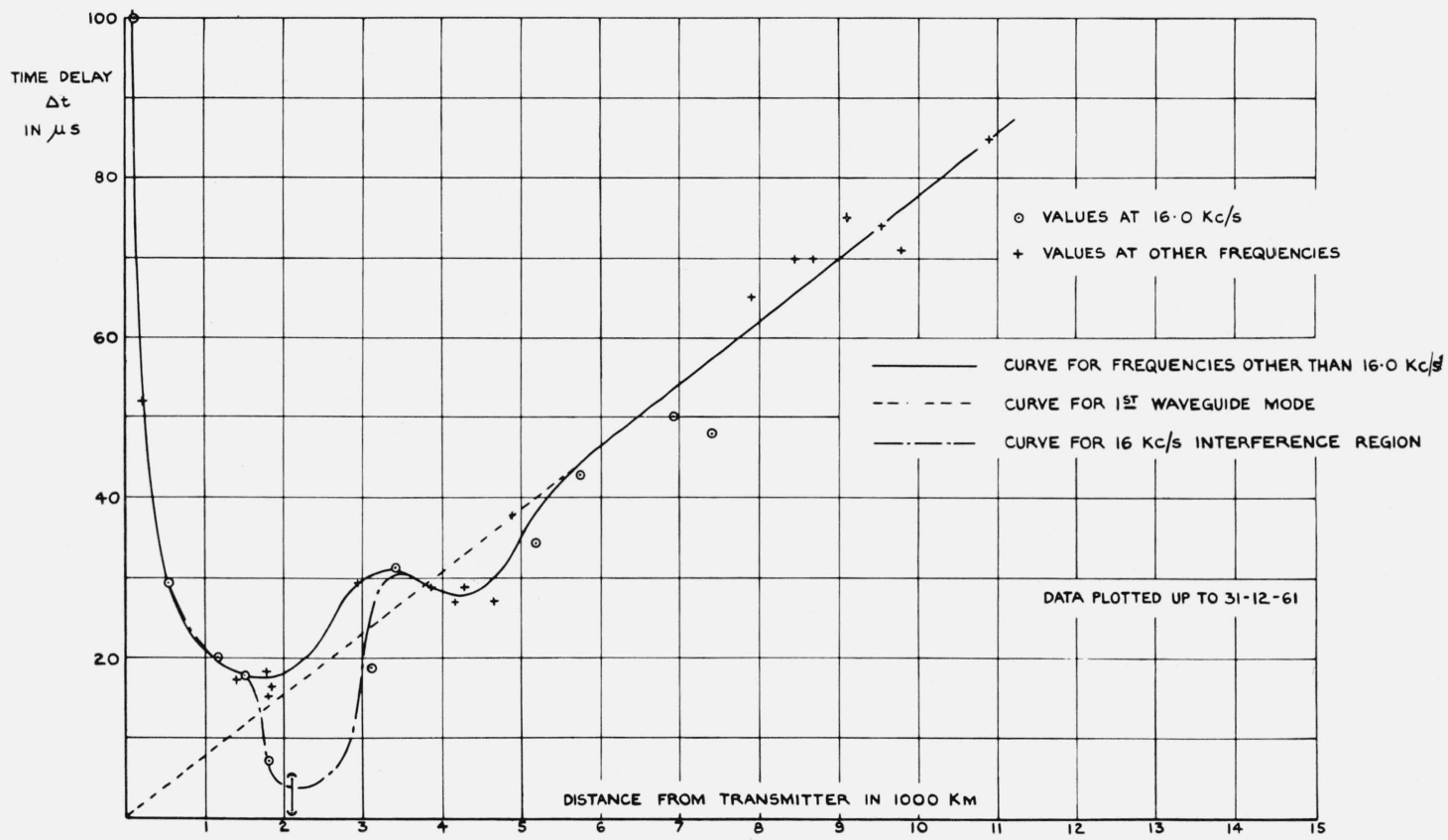

FIGURE 3. Variation in diurnal change of transmission time with distance from the transmitter. 

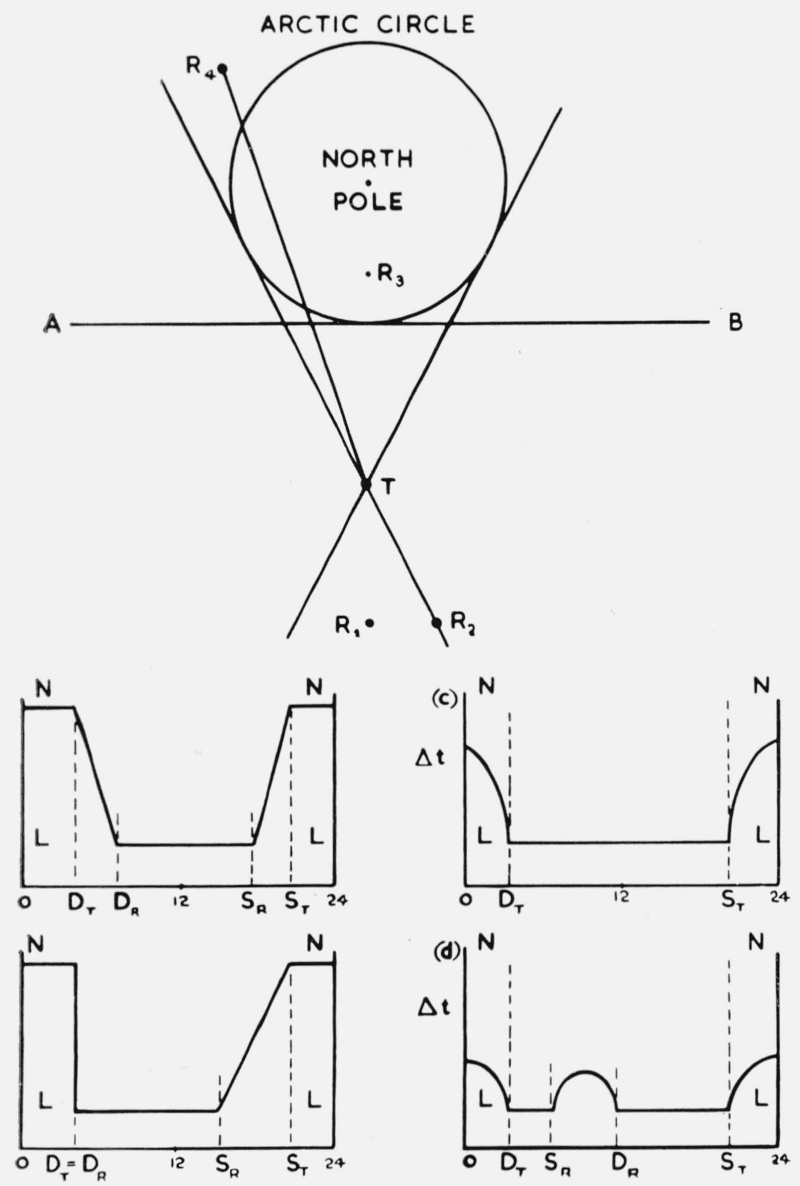

Insets (a)(b)(c)(d) show the delay $\Delta t$ plotted against local time at $T$ for the receiving sites $R_{1}, R_{2}, R_{3}$ and $R_{4}$. $D_{T}$ and $S_{T}$ are the times of dawn and sunset at $T, D_{R}$ and $S_{R}$ refer to the appropriate recejving sites, The lines $N$ and $L L$ show the steady values corresponding to the path all dark or all light.

Figure 4. Diurnal variations of delay in arctic regions.

For a receiver at $R_{3}$ within the Arctic Circle there will be no time at which the whole path is in darkness and a curve of the form of inset (c) will result. It should be noted that the slow change in the fraction of path in darkness as $A B$ rolls almost at right angles to the join of $T R_{3}$, accounts for the rounded top to the pattern in the midnight hours. The time of maxim um change is at the time when $A B$ is tangential to the circle (i.e., midnight) at the point $Q$ where the path $T R_{3}$ cuts the circle. The time of midnight at $Q$ is calculable from its longitude.

A more complex pattern is given for a receiver at $R_{4}$ so sited that the path $T R_{4}$ crosses and recrosses the Arctic Circle. For such a path there are two periods each day when there is daylight for all the path. These are between dawn at $T$ and sunset at $R_{4}$ and between dawn at $R_{4}$ and sunset at $T$. Between times there is darkness for part of the path and the delay increases. If the latitudes of $T$ and $R_{4}$ are the same the delays in each period of partial darkness will be the same, otherwise that period
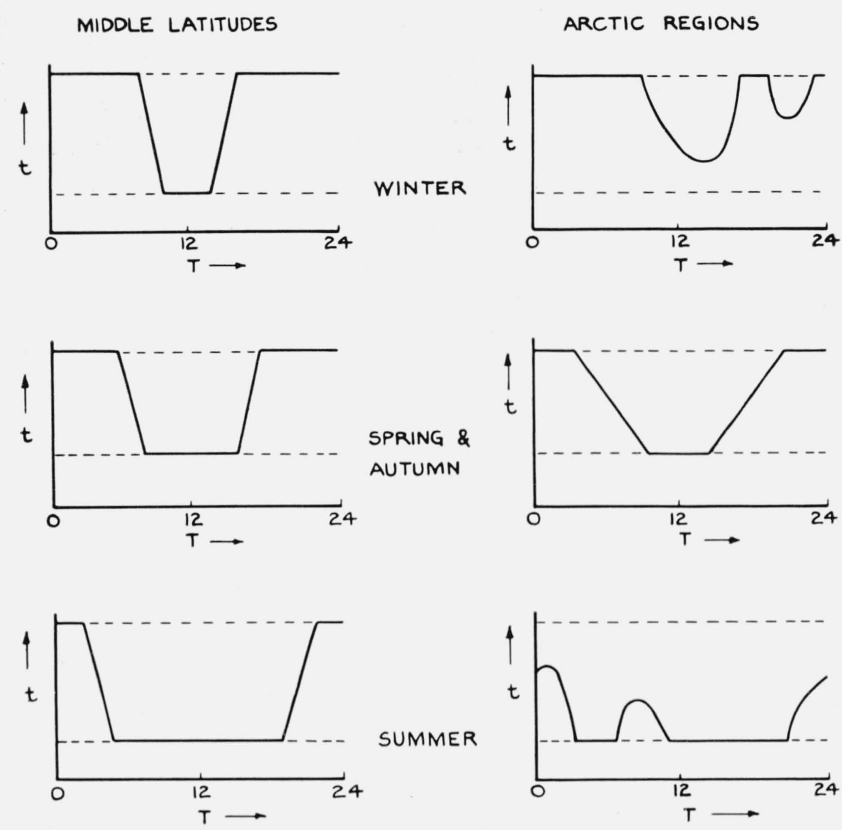

$t=$ TRANSIT TIME OF SIGNAL

$T=$ LOCAL TIME AT TRANSMITTER

Figure 5. Phase patterns at various seasons.

corresponding to darkness at the lower latitude end of the path will have the greater delay.

The path between the transmitter at Seattle (NPG) and the receiving site at Farnborough crosses and recrosses the Arctic Circle in the same way as $T R_{4}$ of figure 4 .

The above explanation has been given in terms of ground sunrise and sunset largely because these are more definite than the more accurate concepts of the times when, looking from the daytime reflection height, the sun is seen to rise above or set below the upper boundary of the ozonosphere. Defining sunrise and sunset in this way for reflection heights of $67 \mathrm{~km}$ and ozonosphere extending to $35 \mathrm{~km}$ the midnight sun at the reflecting layer would be seen as far south as $60^{\circ} 51^{\prime} \mathrm{N}$.

This effect could be allowed for in figure 3 by considering the line $A B$ as rolling round the circle of $60^{\circ}$ $51^{\prime} \mathrm{N}$ latitude instead of the Arctic Circle. It is to be noted that this latitude is that of the Shetland Isles, the southern tip of Greenland or Anchorage in Alaska and that for the purpose of this discussion of VLF propagation the "Arctic" is not confined within the Arctic Circle.

\section{Seasonal Variation in Diurnal Phase Change}

Consider an E-W path at middle latitudes as that discussed in section 2. With the change in the seasons $D_{T}$ and $S_{T}$ (and likewise $D_{R}$ and $S_{R}$ ) will come closer together for the short days of winter and 
separate for the long summer days. The left-hand set of diagrams of figure 5 shows the corresponding lengthening of the trapezium in going from midwinter through the equinox to midsummer. It is to be noted that the basic form of the change pattern does not vary with season, and that $\Delta t$ remains substantially constant.

Figure 4 is drawn for midsummer day; as the year progresses the circle to which $A B$ is tangential shrinks and, by the autumnal equinox, condenses on the pole. The line $A B$ then crosses the pole, which is in darkness until the vernal equinox, and progresses so as to reach the Arctic Circle from the other side at the winter solstice. Consider the effect of the shrinking of the circle to which $A B$ is tangential. In the case of the path $T R_{3}$ as soon as the circle shrinks north of $R_{3}$, the diurnal change of delay will be modified from the form of figure $4 \mathrm{c}$ to that of inset (a). Likewise as the circle shrinks so as not to cut the line $T R_{4}$, there will be but one period of the day when there is daylight for the whole length of the path, and furthermore, there will be a period when there is darkness over the whole path - with these changes the diurnal change pattern for a path corresponding to figure $4 \mathrm{~d}$ will become similar to that of figure 4a. When the line $A B$ approaches the Arctic Circle at midwinter there will be a state when there will be two periods each day when there will be darkness over the whole path and two when the path will be part dark part light, but no period of daylight for the whole path. This is complementary to the midsummer state in which there is no period for which the whole path is in darkness.

The diurnal change patterns corresponding to such a path as $T R_{4}$ are shown in the right hand column of figure 5 . It will be noticed that, unlike those of the left-hand column, these patterns change in form with season, and that $\Delta t$ cannot have its full value during periods when the path is not both all dark and all light on the same day. The curves for this case illustrate the variation along the path Farnborough-Seattle.

\section{Measured Phase Change Patterns}

All the measurements recorded here have been made during the midsummer period when the peculiarities of the Arctic paths would be most marked.

The paths monitored were
(a) GBR (Rugby)
$16.0 \mathrm{kc} / \mathrm{s}$ to
Sondrestrom
(b) NPG (Seattle) $18.6 \mathrm{kc} / \mathrm{s}$ to
Farnborough
(c) NPG (Seattle)
$18.6 \mathrm{kc} / \mathrm{s}$ to Bod $\varnothing$
(d) NPM (Hawaii) $\begin{gathered}19.8 \mathrm{kc} / \mathrm{s} \text { to } \\ \text { Bod } \varnothing\end{gathered}$
June 1961
May 1961
June 1961
June 1961

\begin{tabular}{|c|c|c|c|c|c|c|}
\hline Station.... & GBR & NPG & NPM & Bod $\emptyset$ & $\begin{array}{l}\text { Sondre- } \\
\text { strom }\end{array}$ & $\begin{array}{c}\text { Farn- } \\
\text { borough }\end{array}$ \\
\hline $\begin{array}{l}\text { Latitude } \\
\text { Longitude......... }\end{array}$ & $\begin{array}{r}52^{\circ} 22^{\prime}, \mathrm{N} \\
1^{\circ} 11^{\prime} \\
\mathrm{W}\end{array}$ & 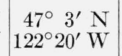 & $\begin{array}{r}21^{\circ} 19^{\prime} \mathrm{N} \\
157^{\circ} 50^{\prime} \mathrm{W}\end{array}$ & $\begin{array}{l}67^{\circ} 18^{\prime}, \mathrm{N} \\
14^{\circ} 26^{\prime} \mathrm{E}\end{array}$ & $\begin{array}{l}67^{\circ} 00^{\prime} \mathrm{N} \\
50^{\circ} 59^{\prime} \mathrm{W}\end{array}$ & $\begin{array}{r}51^{\circ} 17^{\prime} \mathrm{N} \\
0^{\circ} 46^{\prime} \mathrm{W}\end{array}$ \\
\hline
\end{tabular}

The results of the measurements are summarized in the following table:

TABLE 1

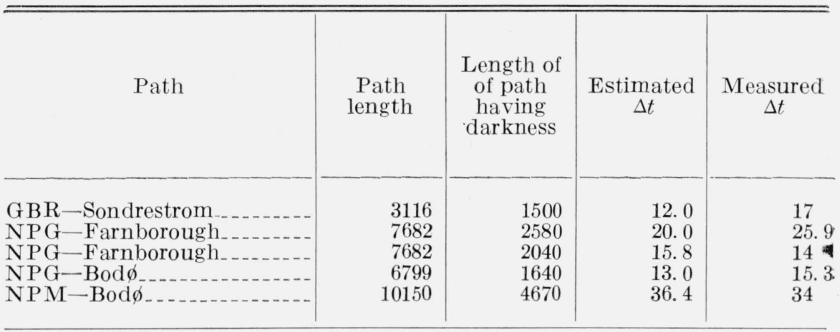

Distances expressed in $\mathrm{km}, \Delta t$ expressed in $\mu$ sec.

In table 1 the second column shows the length of the path between transmitter and receiver. During the midsummer period, part of this path is in daylight at all times, and part will have times of light and dark. The length of the part changing from night to day on the day of measurement is shown in the third column. For the path NPG-Farnborough there are two entries the first corresponding to daynight changes at the western and the second corresponding to those at the eastern end of the path. The lengths quoted in column 3 are calculated on the basis of sunrise and sunset at an ionospheric height of $67 \mathrm{~km}$, the sun being taken to rise or set not at the ground horizon, but at that of an ozonosphere extending to a height of $35 \mathrm{~km} .^{2}$

Of the five paths in the table only the first is short enough for the propagation of other than the first waveguide mode. For the other four the appropriate values of $\Delta t$ can be estimated by reference to the straight line of figure 3 . These estimated values of $\Delta t$ shown in column 4 of the table agree reasonably well with the measured values in the last column. The greatest difference is $5.9 \mu$ sec of which some part is likely to be due to experimental error.

For the shortest path, GBR-Sondrestrom, the path length was not great enough to justify the assumption that only the first mode was present with appreciable amplitude. However the estimated value of $12 \mu \mathrm{sec}$ was based on this assumption-the discrepancy between this and the measured value of $17 \mu$ sec probably arises from the presence of the

2 The two figures of 67 and $35 \mathrm{~km}$ assumed for this calculation were based upon the following consideration. Measurer ents [Bracewell, 1951], of daytime effective height for VLF reflection made at near vertical incidence have given values of about $72 \mathrm{~km}$. Because the effective height at glancing angle is expected to be of about $72 \mathrm{~km}$. Because the effective height at glancing angle is expected to be than the true height, $67 \mathrm{~km}$ seem ed a reasonable estimate of the true height for than the true height, $67 \mathrm{~km}$ seemed a reasonable estimate of the true height for
reflection at large angles of incidence. The upper height of the ozonosphere is not definite but the value of $35 \mathrm{~km}$ was based upon the surveys of measured data published by Mitra [1952] and by Dütsch [1960]. The important parameter is the difference between these heights, that is the height of the reflecting layer above the ozonosphere. The value of $32 \mathrm{~km}$ which results from the above assumptions leads to reasonable agreement between theoretical and experimental values of $\Delta t$. 


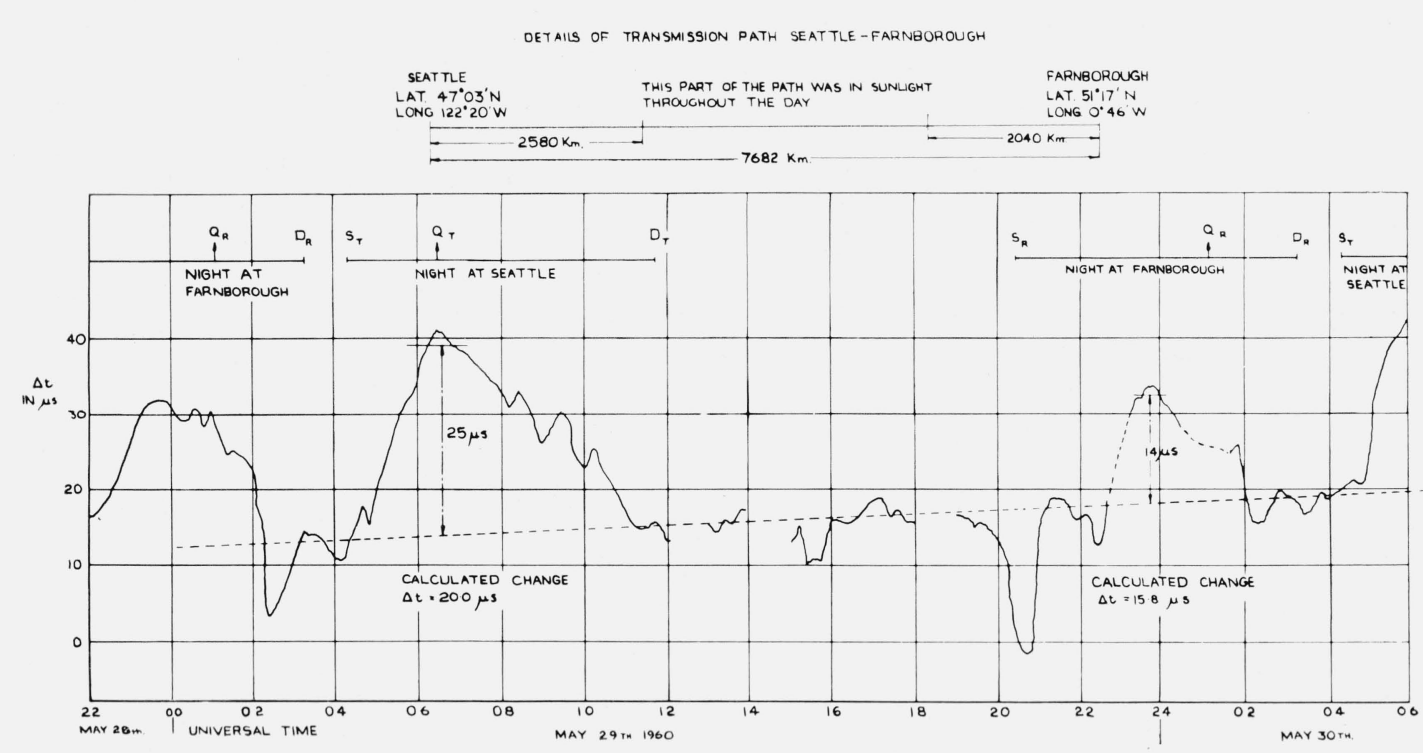

Figure 6. Diurnal pattern for path Seattle-Farnborough.

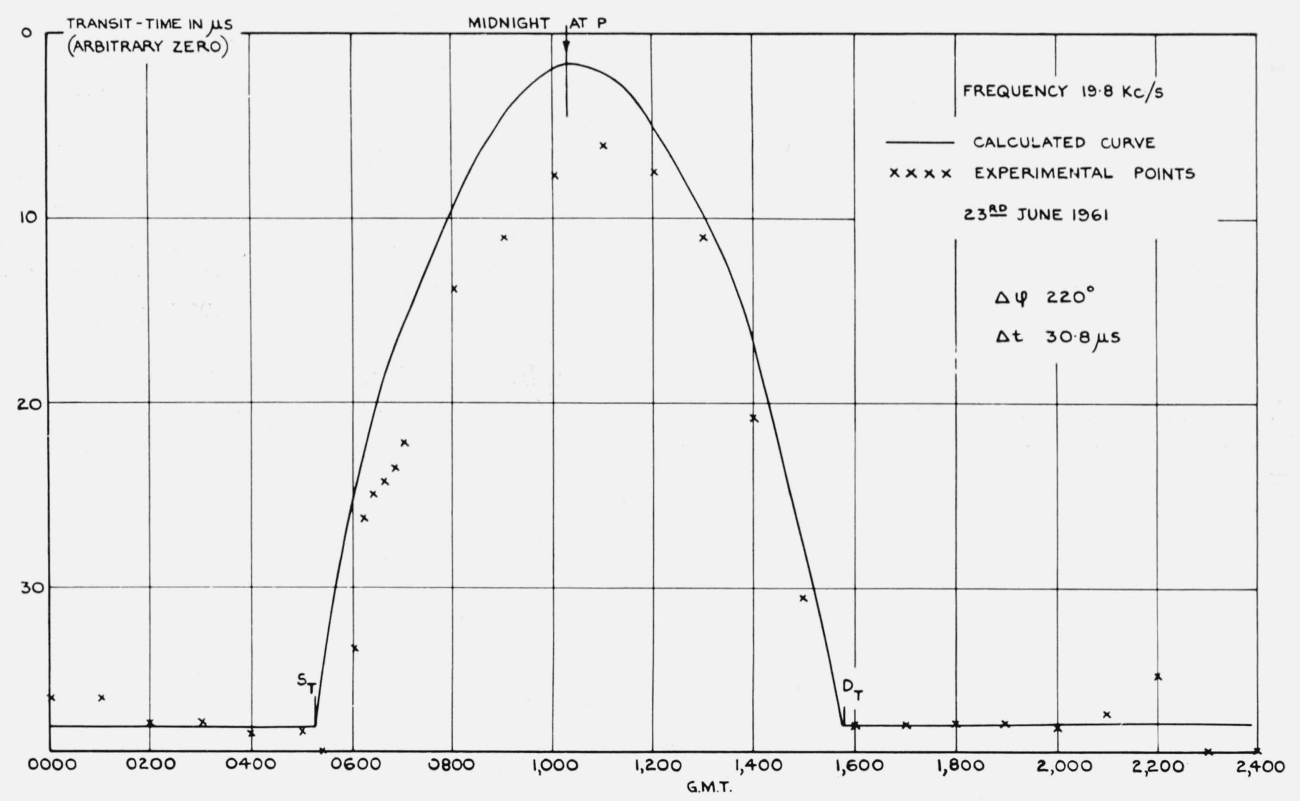

Figure 7. Diurnal change curve for NPM at Bod $\phi$.

higher modes. It is to be expected that their presence would tend to increase $\Delta t$ above the value appropriate to the propagation of a single mode.

Some of the observed diurnal change curves are given in figures 6 through 8 . For the path NPGFarnborough a typical curve is shown in figure 6 . This has two peaks in it, one corresponding to darkness at each end in turn. The curve has the general shape of that shown in figure 5 for Arctic summer. On the diagram are marked the times of high altitude sunrise and sunset $\left(D_{T}\right.$ and $\left.S_{T}\right)$. Also marked are the calculated changes (as given in column 4 of the table) and times of maximum change (midnight at $P$ ).
Similar data are given in figures 7 and 8 which relate respectively to the paths NPM-Bodø and NPG-Bod $\varnothing$.

\section{Conclusions}

(a) The diurnal changes in transmission time for arctic paths differ from those expected on paths at middle latitudes.

(b) That these changes vary in form and amplitude with season.

(c) That these effects can extend to a latitude of about $60^{\circ} 51^{\prime} \mathrm{N}$.

(d) That the seasonal variations can be estimated by simple methods. 


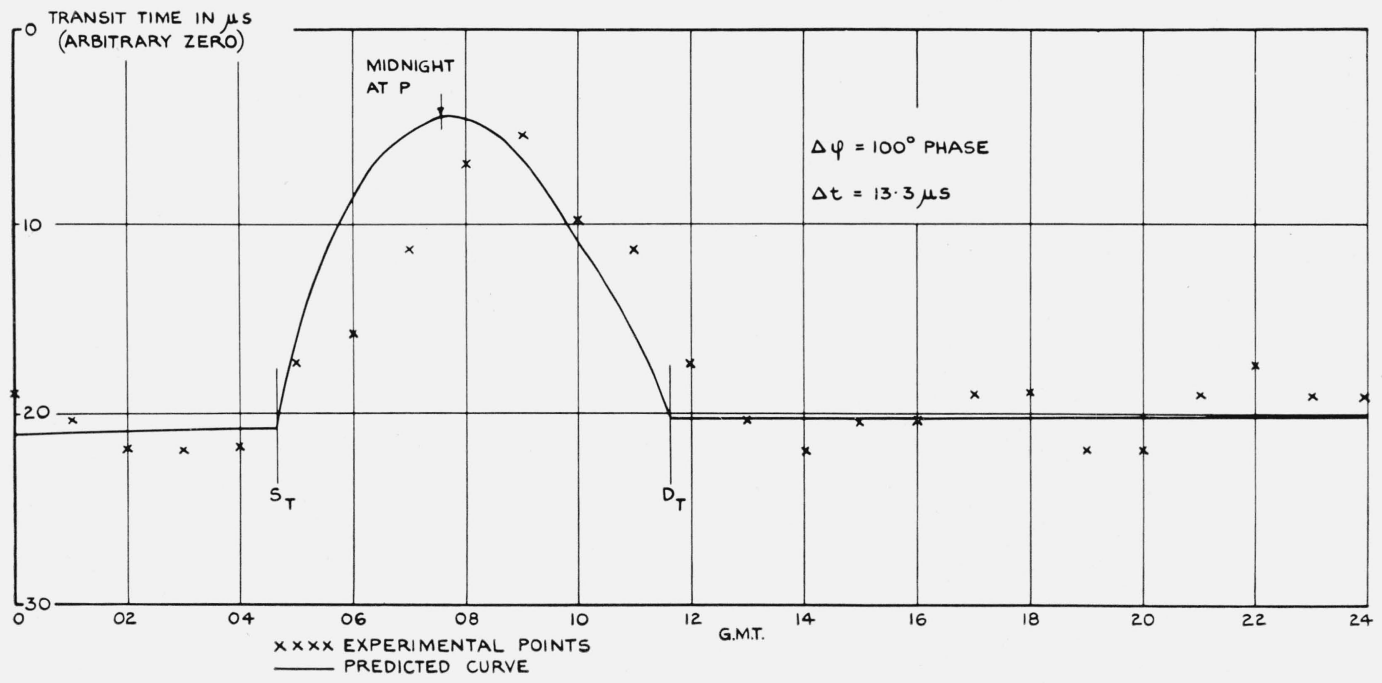

Figure 8. Diurnal change curve for NPG at Bod $\phi$.

The author acknowledges with gratitude the help of many colleagues in the work of mounting the experiments and analyzing the recorded data. The recordings made within the Arctic Circle could not have been made without the help of the Royal Norwegian Air Force at Bodø and the United States Air Force at Sondrestrom who welcomed us and our equipment and whose readiness to help knew no bounds.

\section{References}

Blackband, W. T. (Nov.-Dec. 1961), Effects of the ionosphere on VLF navigational aids, J. Res. NBS 65D (Radio Prop.), No. 6, 575-580.
Blackband, W. T. (1963), Diurnal changes in the time of propagation of VLF waves over single mode paths, Propagation of radio waves at frequencies below $300 \mathrm{kc} / \mathrm{s}$, (Pergamon Press, Oxford.)

Bracewell, R. N., K. G. Budden, J. A. Rat liffe, T. W. Straker, and K. Weekes (1951), The ionospheric propagation of low and very low frequency radiowaves over distance less than $1000 \mathrm{~km}$, Proc. Inst. Elec. Engrs. 98, Part III, 221-236.

Dütsch, H. U. (1960), Vertical ozone distribution from the umkehr effect, Annales de Geophysique T. 16, No. 2, 200207.

Mitra, S. K. (1952), The upper atmosphere, chap. IV, p. 134 (Calcutta, Asiatic Society).

(Paper 68D2-333) 